Supplement of Atmos. Chem. Phys., 19, 15235-15245, 2019

https://doi.org/10.5194/acp-19-15235-2019-supplement

(C) Author(s) 2019. This work is distributed under

the Creative Commons Attribution 4.0 License.

(c) (1)

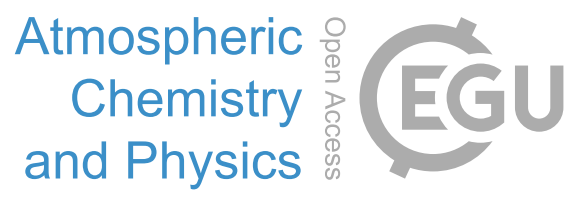

Supplement of

\title{
The regional temperature implications of strong air quality measures
}

Borgar Aamaas et al.

Correspondence to: Borgar Aamaas (borgar.aamaas@cicero.oslo.no)

The copyright of individual parts of the supplement might differ from the CC BY 4.0 License. 
3 Table S1: Relative uncertainties in the radiative forcing applied in the Monte Carlo analysis.

\begin{tabular}{lrl}
\hline Species & Relative uncertainty (1 SD) & Source \\
\hline BC & $39 \%$ & Myhre et al. (2013a) \\
OC & $33 \%$ & Myhre et al. (2013a) \\
SO2 & $34 \%$ & Myhre et al. (2013a) \\
NOx & $73 \%$ & Myhre et al. (2013b) \\
CO & $15 \%$ & Myhre et al. (2013b) \\
VOC & $25 \%$ & Myhre et al. (2013b) \\
CH4 & $10 \%$ & Myhre et al. (2013b) \\
\hline
\end{tabular}

4

\section{Additional figures with other perspectives}

6 Due to masked warming of historical emissions of SLCFs, we are likely overestimating the temperature reduction potential by reducing emissions of warming SLCFs. In SLCP, we are overestimating the temperature reduction potential by approximately

Due to space constraints, the article investigate only some different parameters. As different users may have different interests, we present some additional figures here. The emission perturbations in emission regions Europe, East Asia, rest of the World (ROW), and global shipping for the SLCP and MTFR scenarios compared to the baseline CLE are shown in Figs. S1 and S2, respectively. The total warming and total cooling for SLCP and MTFR relative to CLE are shown in Fig. S3. Figures S4 and S5 show the global temperature response for emission mitigation according to the SLCP and MTFR scenario, respectively, in emission regions Europe, East Asia, rest of the World (ROW), and global shipping. In Fig. S6, we separate ROW into a subset of regions. As ARTP values are not available for these regions, the ARTP value for ROW is applied for all regions. This is a simplification, but gives an indication of what regions can contribute the most in reducing the global and regional temperatures. The remaining figures show the regional and global temperature response in 2035, 2070, and 2100. Figures S7 and S8 present the temperature perturbation for emission regions and emission sectors for SLCP and MTFR scenarios, respectively. Figures $\mathrm{S} 9$ and $\mathrm{S} 10$ give the temperature perturbation for emission sectors and species for SLCP and MTFR scenarios, respectively. 


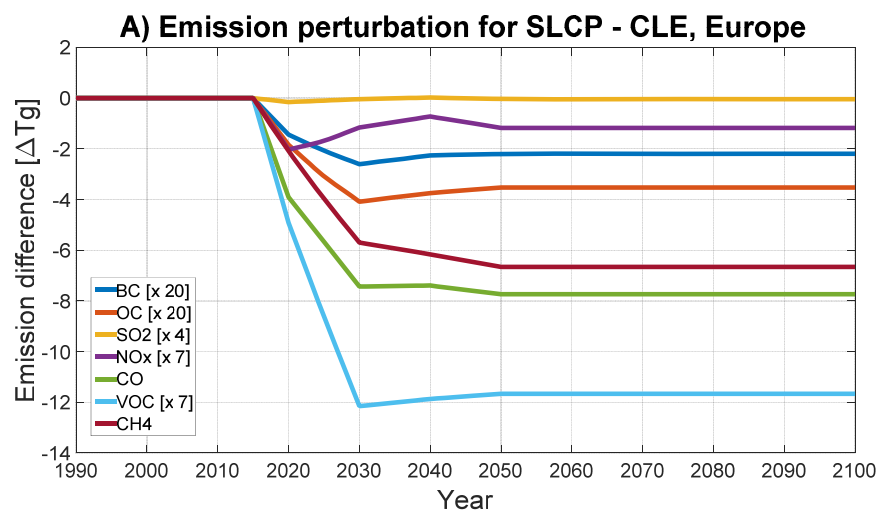

B) Emission perturbation for SLCP - CLE, East Asia

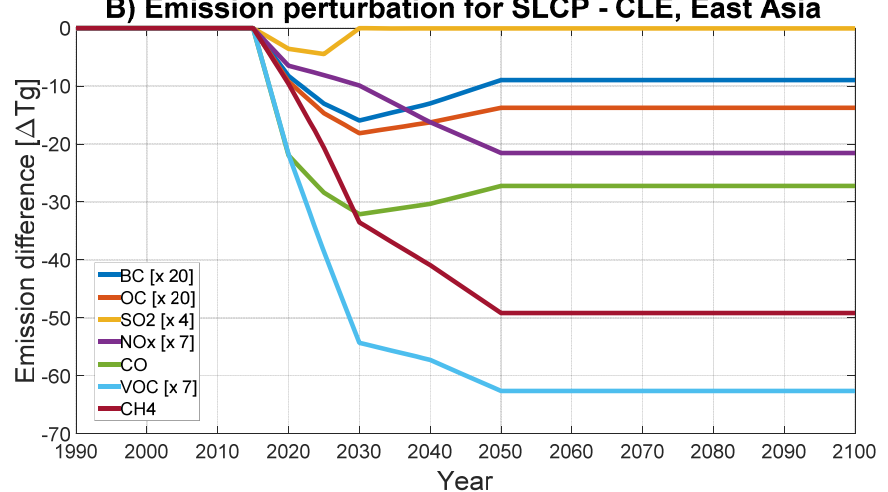

C) Emission perturbation for SLCP - CLE, RoW

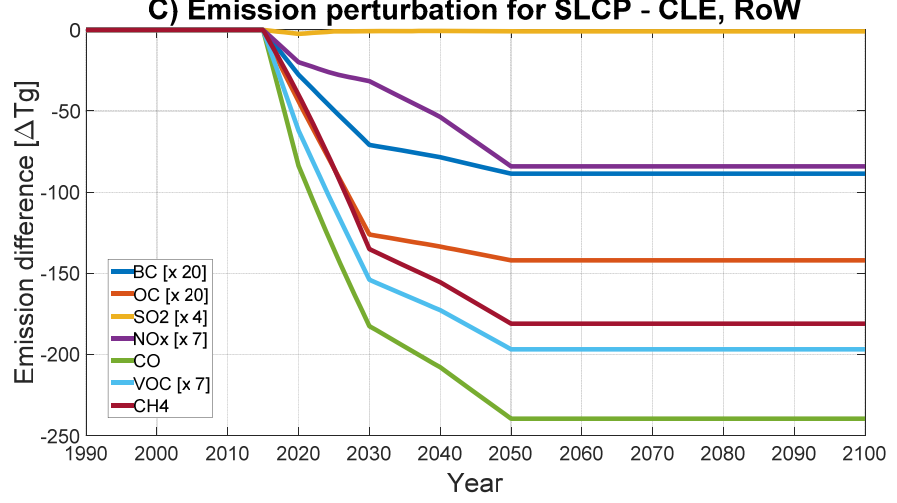

D) Emission perturbation for SLCP - CLE, shipping

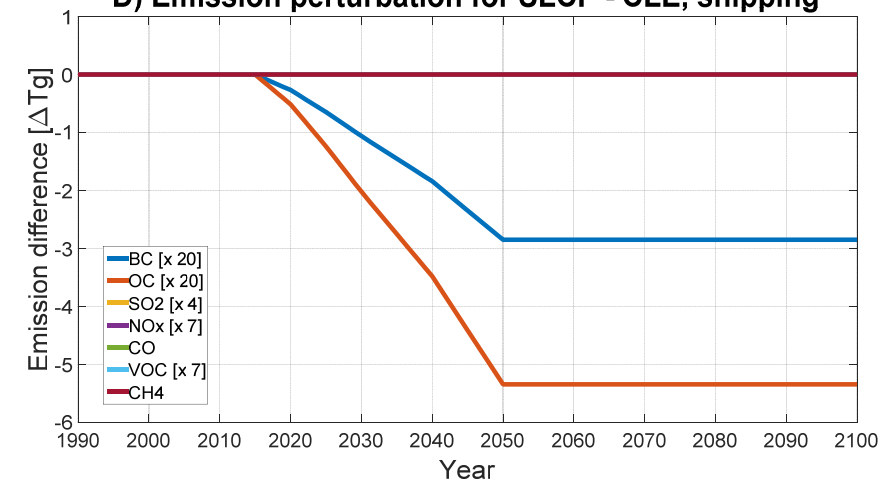

Figure S1: The emission difference between SLCP and CLE for different emission regions. Note the 29 different scales. 


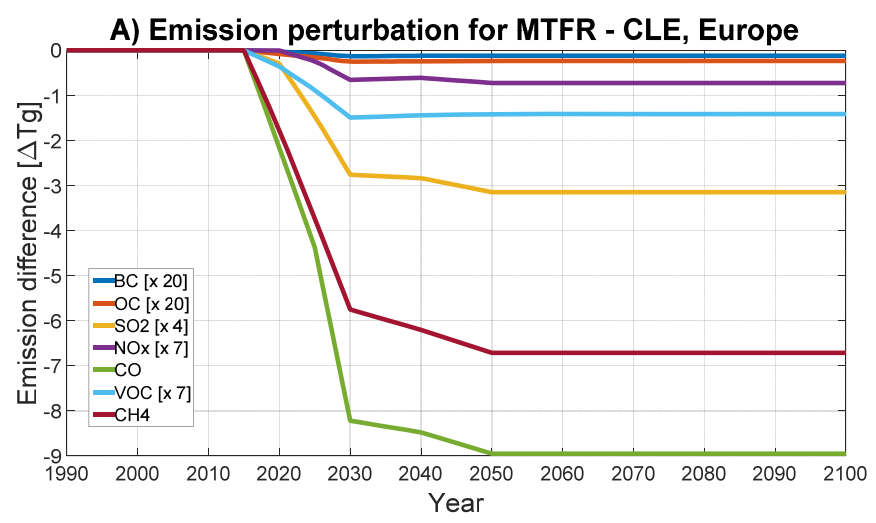

31

B) Emission perturbation for MTFR - CLE, East Asia

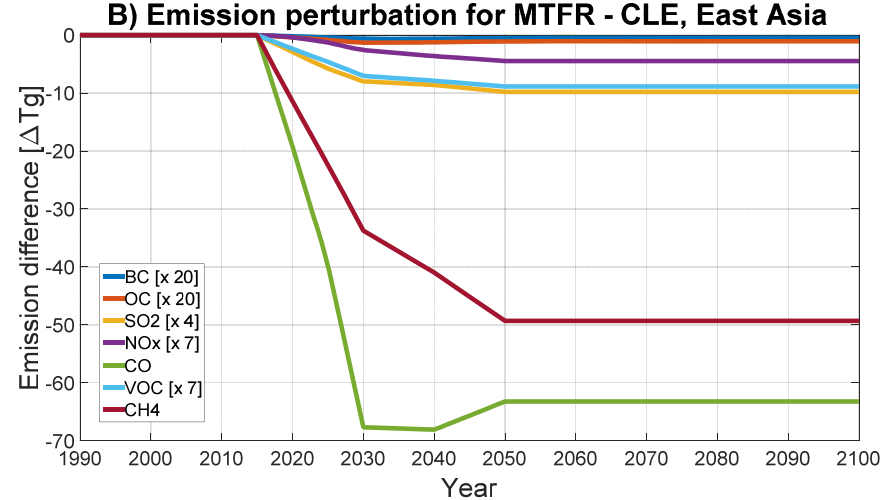

C) Emission perturbation for MTFR - CLE, RoW

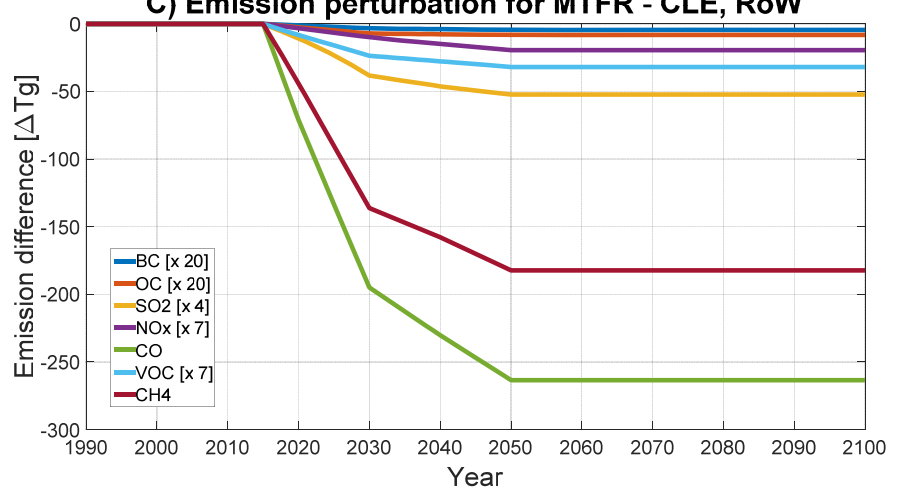

D) Emission perturbation for MTFR - CLE, shipping

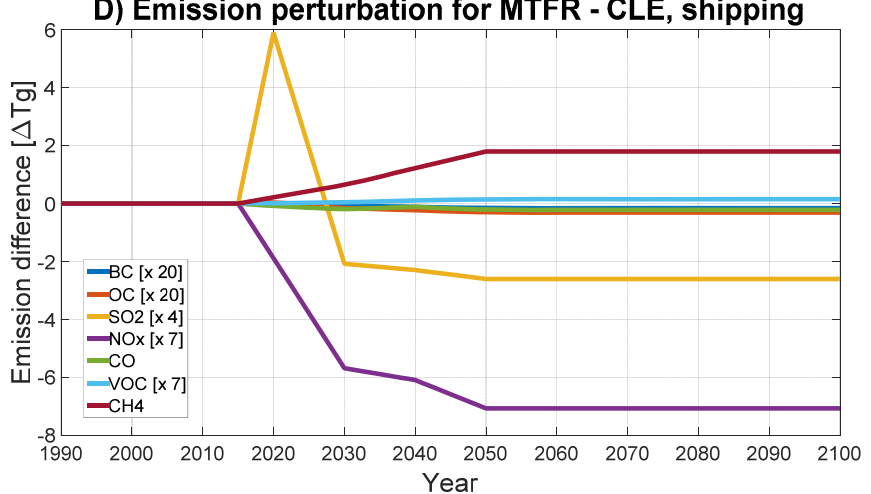

34 Figure S2: The emission difference between MTFR and CLE for different emission regions. Note the 


\section{Global temperature responses for MTFR \& SLCP}

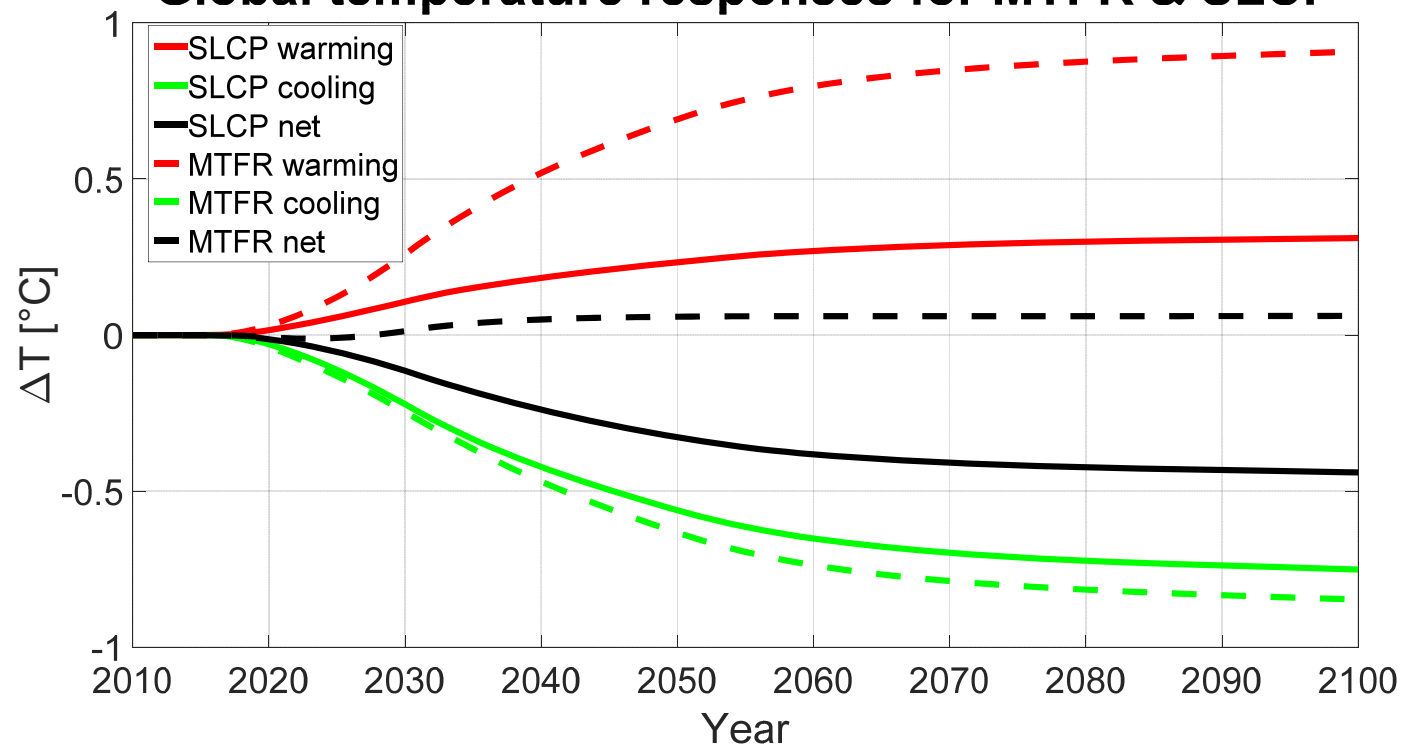

Figure S3: The global temperature response in SLCP and MTFR relative to CLE. The warming and cooling components have been separated. 


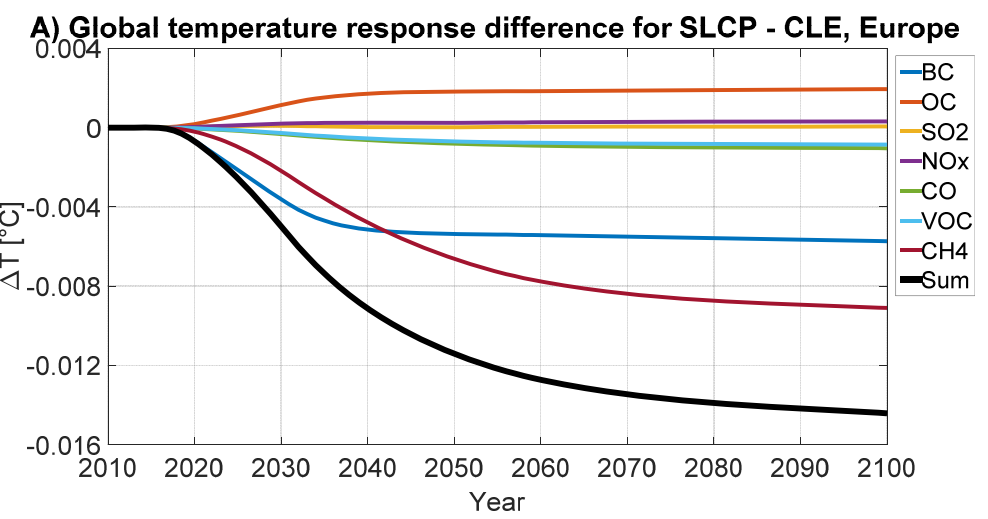

B) Global temperature response difference for SLCP - CLE, East Asia
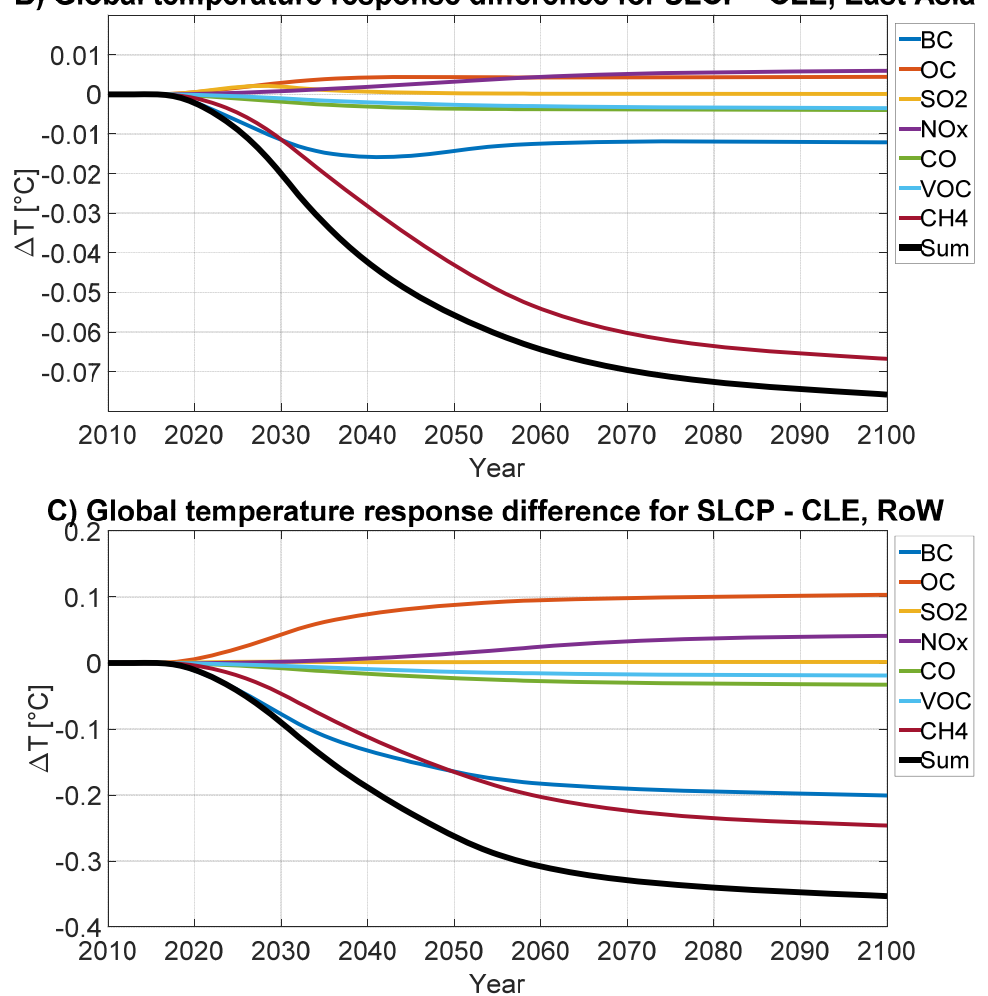

41
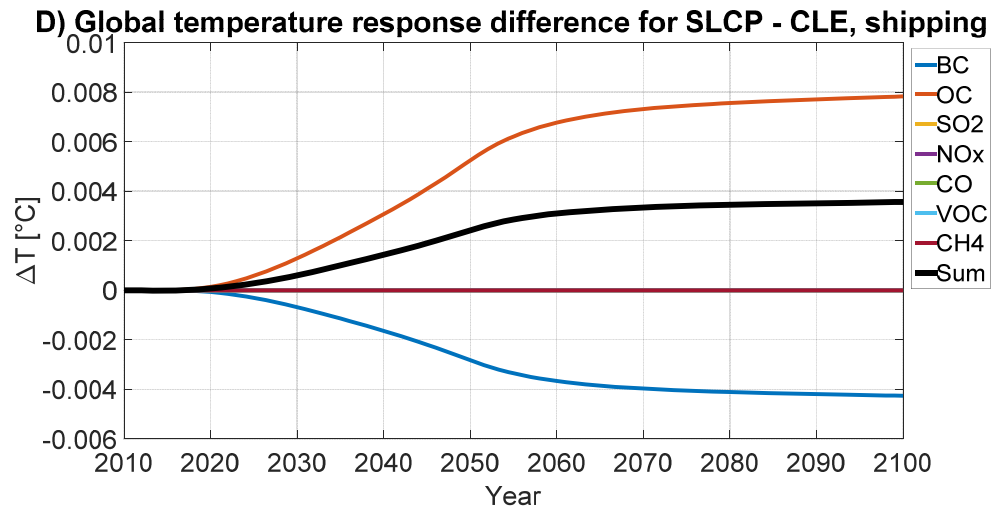

43 Figure S4: The global temperature response due to mitigation of SLCFs in different emission regions relative to baseline CLE. Note the different scales for the SLCP mitigation scenario. 


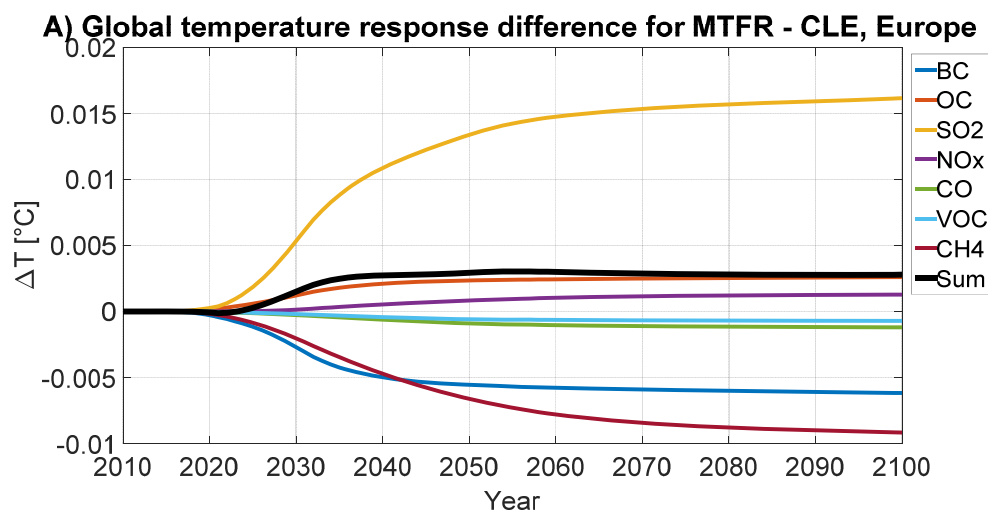

B) Global temperature response difference for MTFR - CLE, East Asia

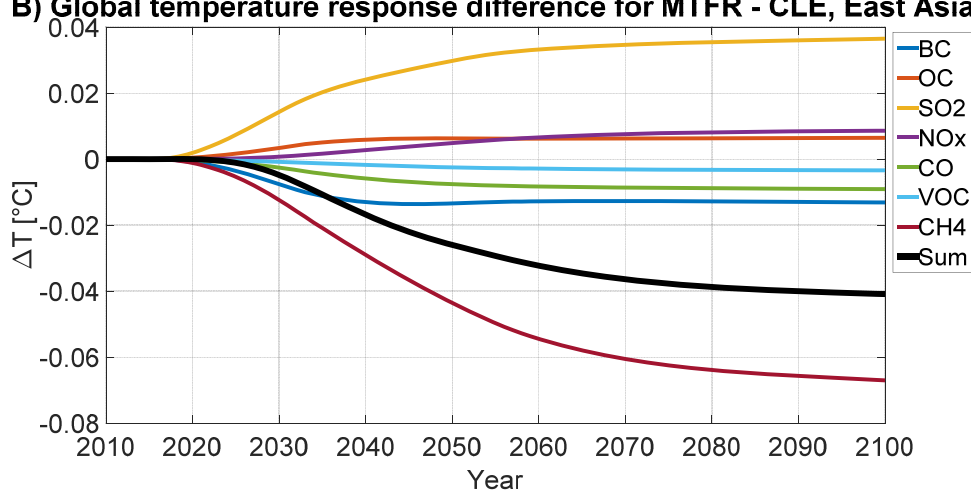

C) Global temperature response difference for MTFR - CLE, RoW

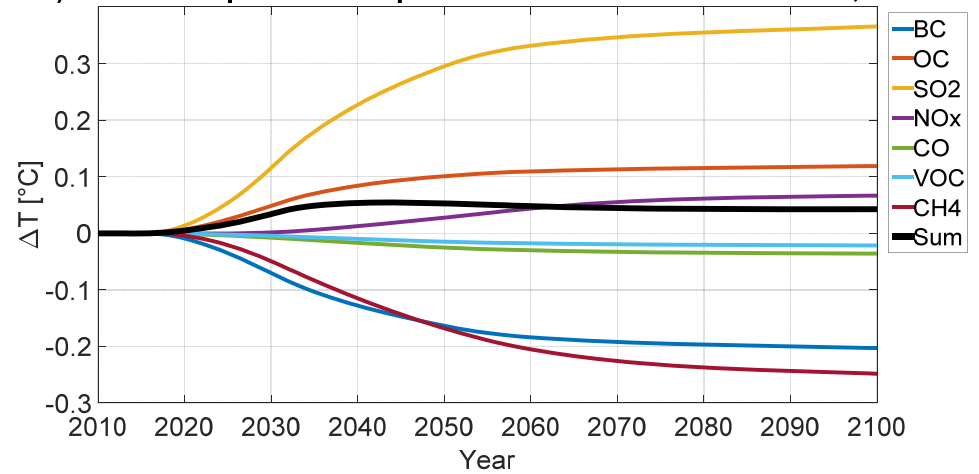

D) Global temperature response difference for MTFR - CLE, shipping

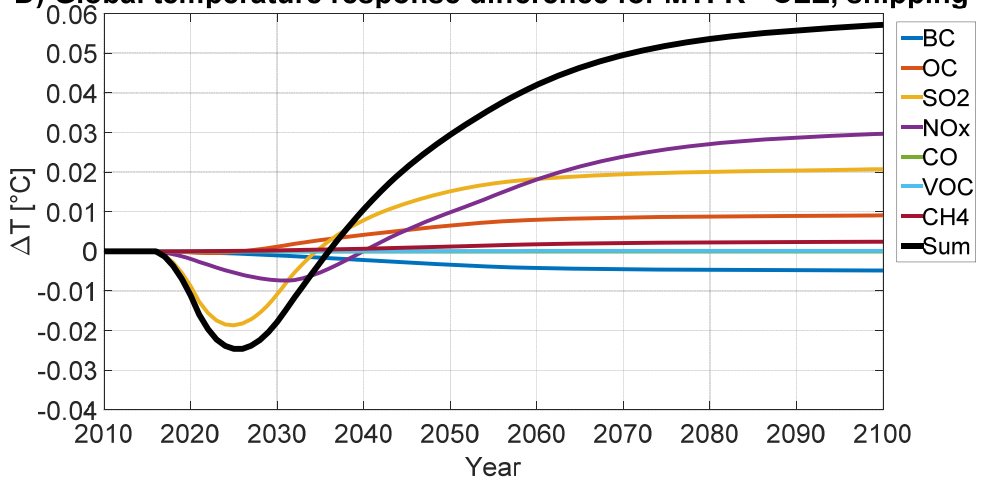

49 Figure S5: The global temperature response due to mitigation of SLCFs in different emission regions relative to baseline CLE. Note the different scales for the MTFR mitigation scenario. 

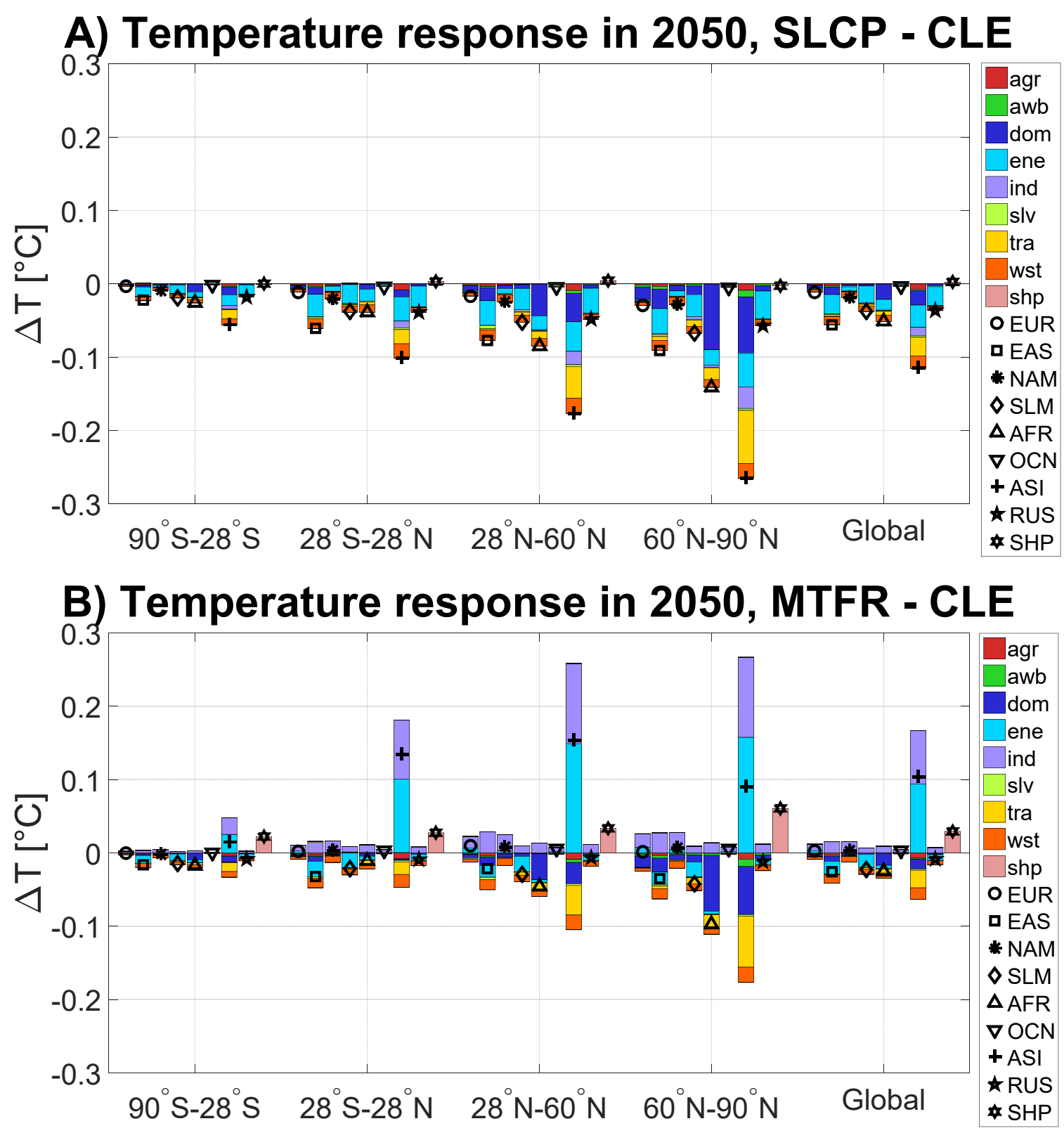

Figure S6: The temperature response in the latitude bands and globally in 2050 for emission regions and emission sectors for SLCP (A) and MTFR scenario (B) relative to baseline CLE. The regions are Europe (EUR), East Asia (EAS), North America (NAM), South and Latin America (SLM), Africa (AFR), Australia and Oceania (OCN), rest of Asia (ASI), Russia and other (RUS), and global shipping (SHP). 

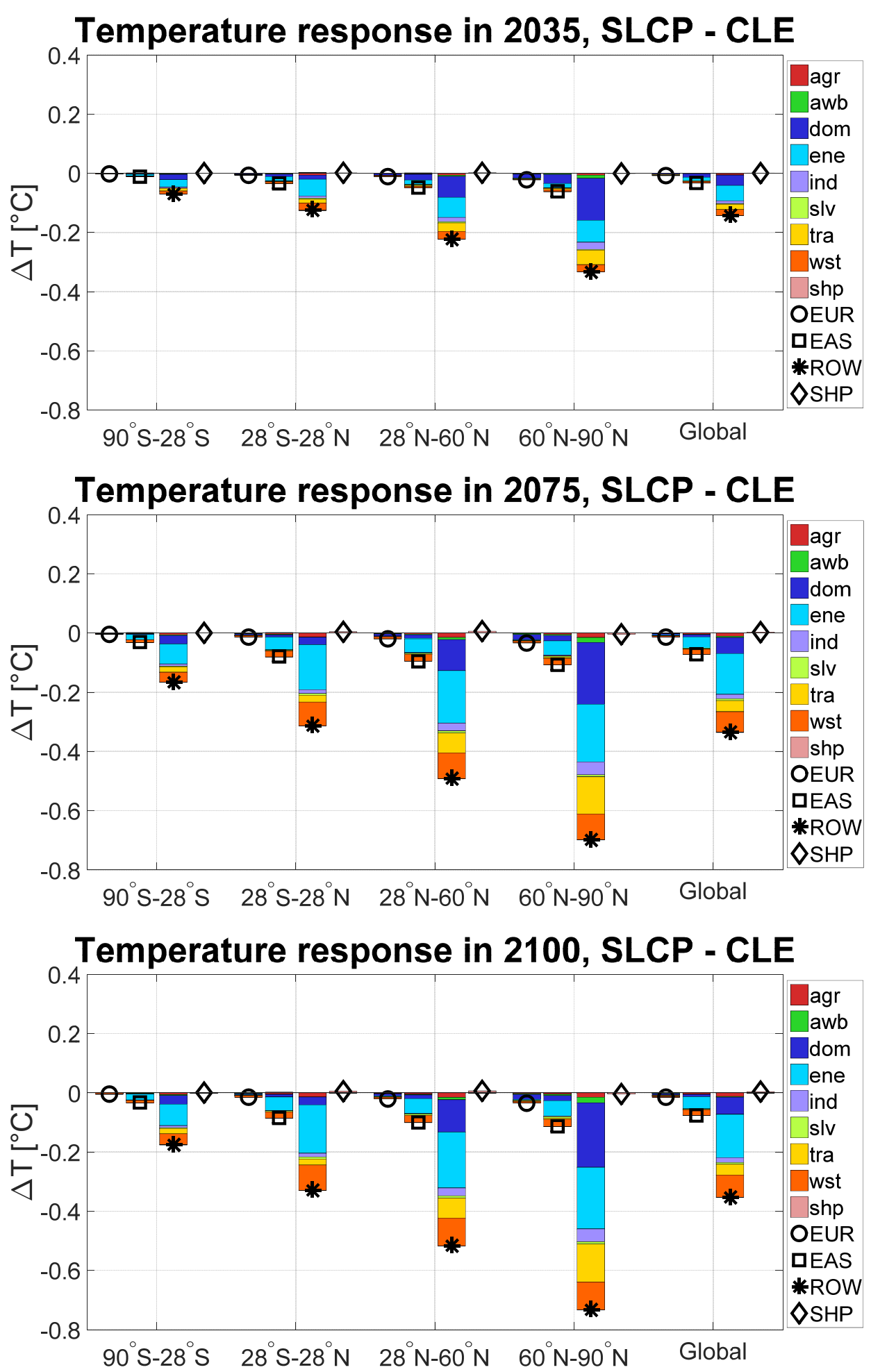

Figure S7: The regional temperature response from the SLCP mitigation scenario relative to baseline CLE 

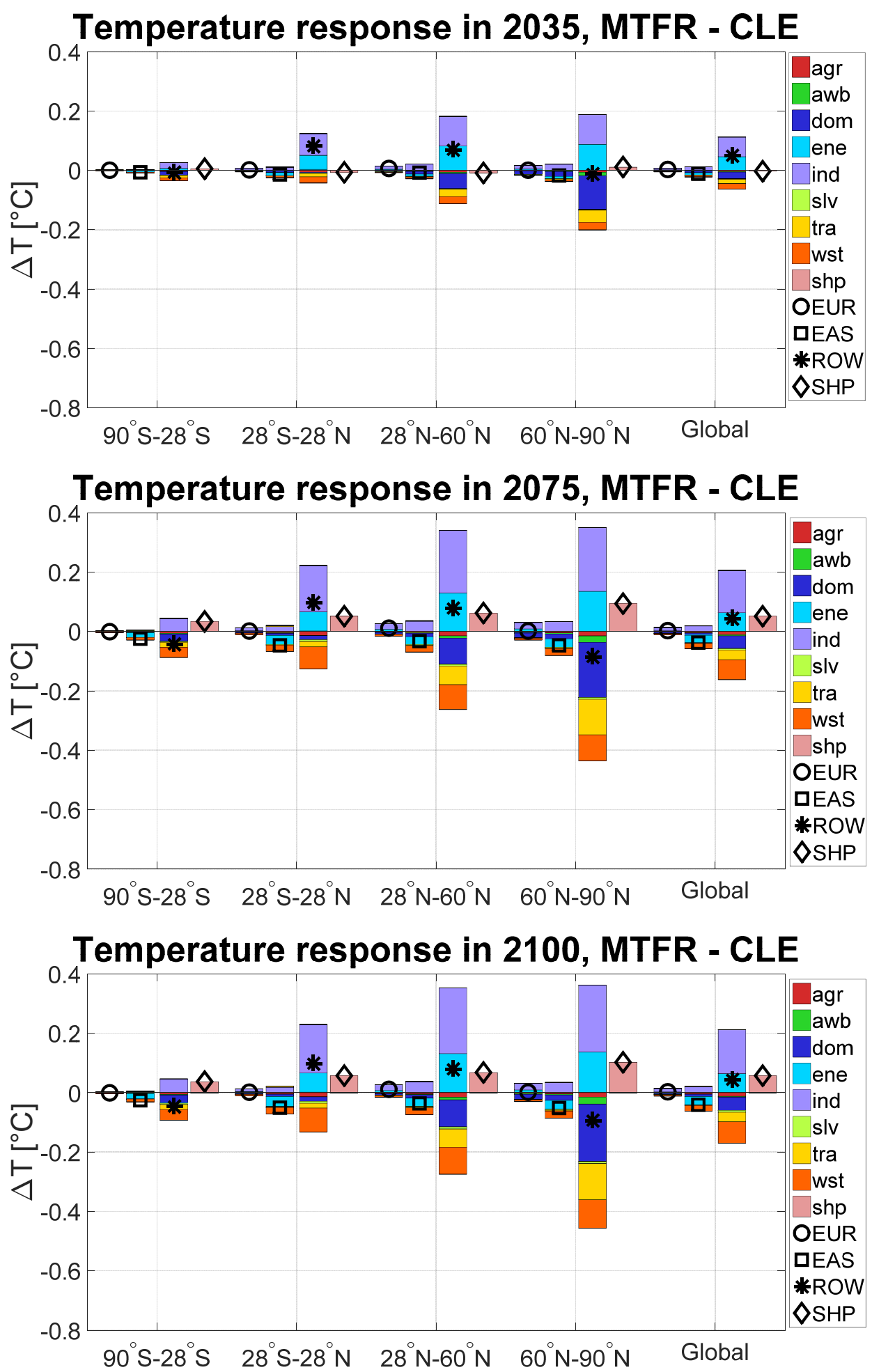
CLE for emission regions and emission sectors in 2035, 2075, and 2100. 

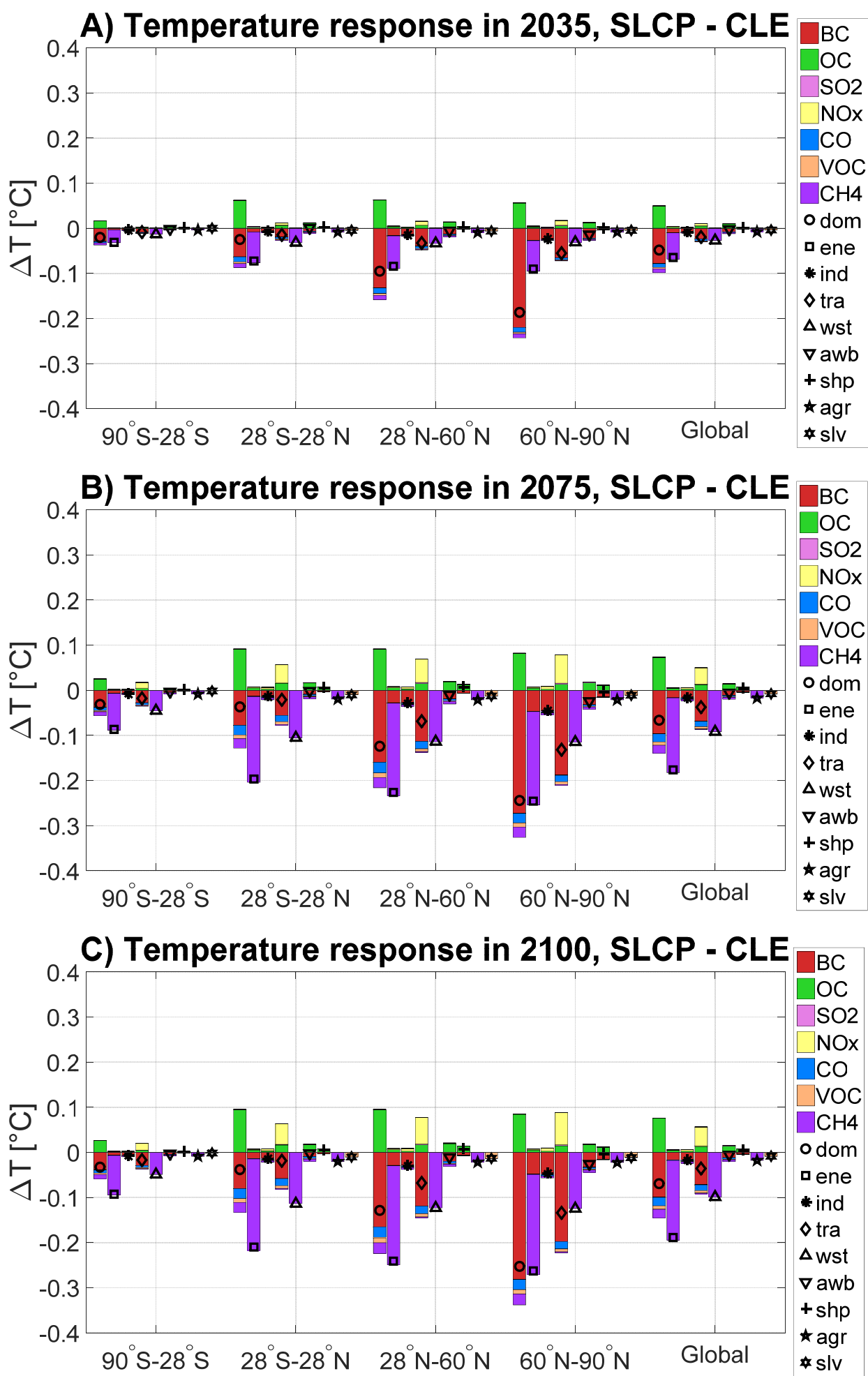

Figure S9: The regional temperature response from the SLCP mitigation scenario relative to baseline CLE 

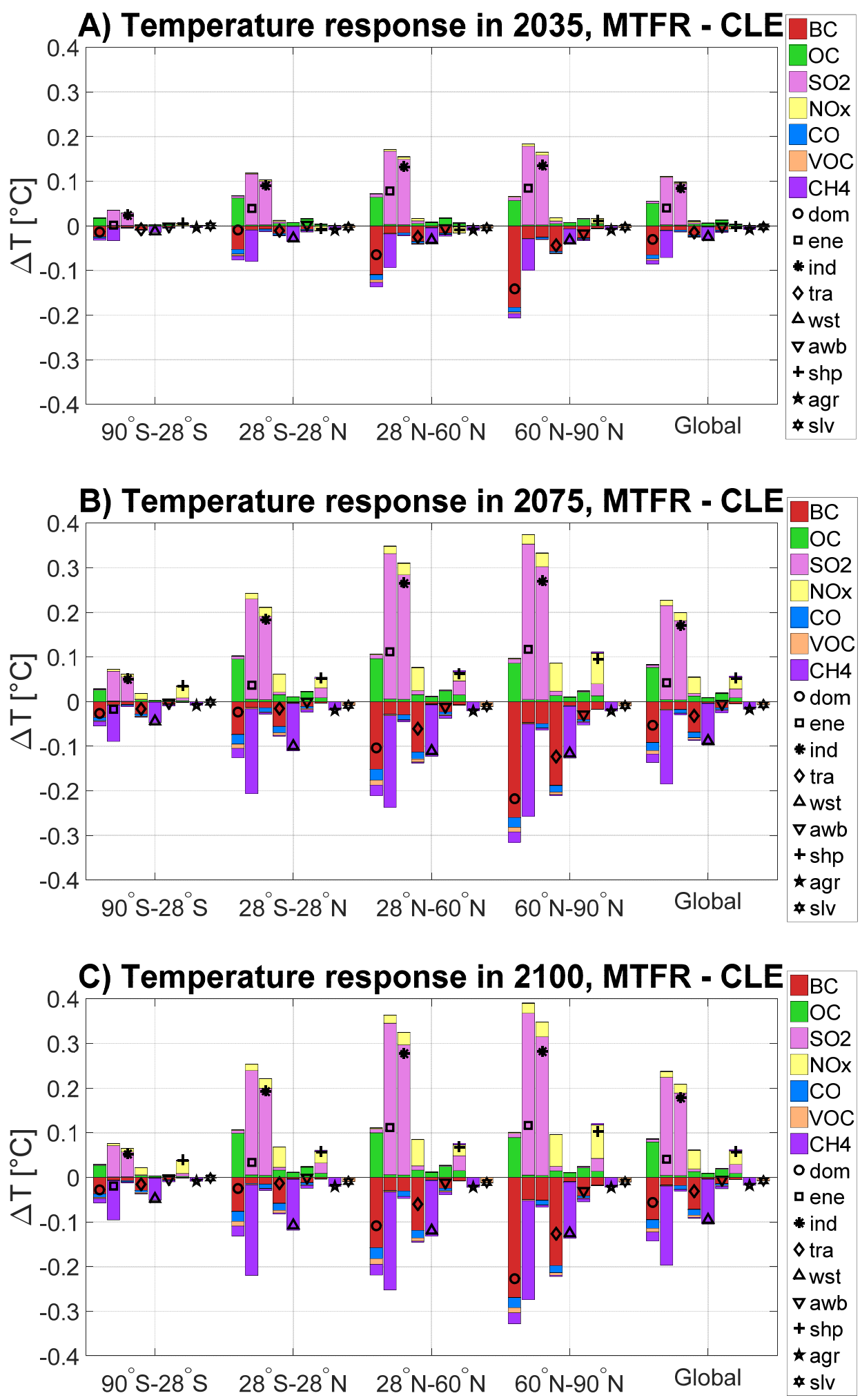

Figure S10: The regional temperature response from the MTFR mitigation scenario relative to baseline CLE for emission sectors and species in 2035, 2075, and 2100. 
80 Myhre, G., Samset, B. H., Schulz, M., Balkanski, Y., Bauer, S., Berntsen, T. K., Bian, H., Bellouin, N., Chin, M., Diehl, T., Easter, R. C., Feichter, J., Ghan, S. J., Hauglustaine, D., Iversen, T., Kinne, S., Kirkevåg, A., Lamarque, J. F., Lin, G., Liu, X., Lund, M. T., Luo, G., Ma, X., van Noije, T., Penner, J. E., Rasch, P. J., Ruiz, A., Seland, $\varnothing$., Skeie, R. B., Stier, P., Takemura, T., Tsigaridis, K., Wang, P., Wang, Z., Xu, L., Yu, H., Yu, F., Yoon, J. H., Zhang, K., Zhang, H., and Zhou, C.: Radiative forcing of the direct aerosol effect from AeroCom Phase II simulations, Atmos. Chem. Phys., 13, 1853-1877, 10.5194/acp-13-1853-2013, 2013a. Myhre, G., Shindell, D., Bréon, F.-M., Collins, B., Fuglestvedt, J. S., Huang, J., Koch, D., Lamarque, J.-F., Lee, D., Mendoza, B., Nakajima, T., Robock, A., Stephens, G., Takemura, T., and Zhang, H.: Anthropogenic and Natural Radiative Forcing, in: Climate Change 2013: The Physical Science Basis. Contribution of Working Group I to the Fifth Assessment Report of the Intergovernmental Panel on Climate Change, edited by: Stocker, T. F., Qin, D., Plattner, G. K., Tignor, M., Allen, S. K., Boschung, J., Nauels, A., Xia, Y., Bex, V., and Midgley, P. M., Cambridge University Press, Cambridge, United Kingdom and New York, NY, USA, 2013b. 